\title{
Which Factors Affect Survival in Patients With Upper Limb Osteosarcoma?
}

\author{
DAVID J. RESTREPO ${ }^{1}$, MARIA T. HUAYLLANI ${ }^{1}$, DANIEL BOCZAR ${ }^{1}$, ANDREA SISTI ${ }^{1}$, \\ AARON C. SPAULDING ${ }^{2}$, RICKEY E. CARTER ${ }^{2}$, STEVEN L. MORAN ${ }^{3}$, \\ ALEXANDER S. PARKER ${ }^{4}$, GALEN PERDIKIS ${ }^{5}$ and ANTONIO J. FORTE ${ }^{1}$ \\ ${ }^{1}$ Division of Plastic Surgery and Robert D. and Patricia E. Kern Center for the \\ Science of Health Care Delivery, Mayo Clinic, Jacksonville, FL, U.S.A.; \\ ${ }^{2}$ Department of Health Science Research, Mayo Clinic, Jacksonville, FL, U.S.A.; \\ ${ }^{3}$ Division of Plastic Surgery, Mayo Clinic, Rochester, MN, U.S.A.; \\ ${ }^{4}$ Office of Research Affairs, University of Florida, College of Medicine, Jacksonville, FL, U.S.A.; \\ ${ }^{5}$ Department of Plastic Surgery, Vanderbilt University Medical Center, Nashville, TN, U.S.A.
}

\begin{abstract}
Aim: The purpose of this study was to identify patient-, facility-, disease-, and treatment-specific characteristics that increase mortality in patients with upper limb osteosarcoma. Patients and Methods: The National Cancer Data Base $(N C D B)$ was queried for bone cancer. With Cox regression, the demographic, facility, tumor-specific and treatment characteristics were analyzed to identify factors that increased mortality. Results: Cox regression model showed that patients older than 40 years had a significantly higher likelihood of dying from upper limb osteosarcoma than those aged 0-14 years [hazard ratio $(H R)=4.12,95 \%$ confidence interval $(C I)=2.261-7.508]$. Patients with an income of $\$ 38,000-47,999$ $(H R=3.335,95 \% C I=1.694-657)$ or less than $\$ 38,000$ $(H R=2.41,95 \% C I=1.098-5.288)$ were also at greater risk of dying from their tumor. Patients who received radiation therapy $(H R=2.457,95 \% C I=1.056-5.717)$ had a higher likelihood of dying than patients who did not undergo this therapy. Conclusion: Age, gender, income, education, stage at diagnosis, radiation therapy and type of surgery seem to increase mortality from upper limb osteosarcoma.
\end{abstract}

Considered the most frequent primary malignant bone tumor type, osteosarcoma is an aggressive malignancy that mostly metastasizes to the lung (1). It is an uncommon pathology with a yearly incidence of 1.5 to 4 cases per million people (2).

Correspondence to: Antonio Jorge Forte, MD, Ph.D., Mayo Clinic Florida, 4500 San Pablo Road, Jacksonville, Florida 32224, U.S.A. Tel: +1 9049532073, e-mail: ajvforte@yahoo.com.br

Key Words: Osteosarcoma, upper limb, survival, survivors, treatment.
Before the introduction of chemotherapy treatment, osteosarcoma was considered incurable because, even when a surgical resection was thought to have successfully removed the tumor, metastasis appeared in $80-90 \%$ of patients (3). A systematic literature review showed that 5-year survival without chemotherapy was 16\% [95\% confidence interval $(\mathrm{CI})=9-23 \%$ ], increasing to $70 \%$ when treated with three or more chemotherapeutic agents. Current treatment for osteosarcoma has not changed much in the past 30 years, and survival rates have plateaued. New chemotherapeutic agents have not proven to be substantially better than the current treatment (4). Since no new therapy has emerged, we wondered if, from a public health standpoint, mortality for this devastating disease can be reduced. The purpose of our study was to identify patient, facility, disease, and treatment characteristics that increase mortality in patients with upper limb osteosarcoma.

\section{Patients and Methods}

The National Cancer Database (NCDB), jointly sponsored by the American College of Surgeons and the American Cancer Society, collects data from approximately $70 \%$ of patients who were newly diagnosed with cancer in the United States (5). Certified Tumor Registrars are trained to submit information from patient records to the database. Information is then revised for accuracy (5). Our retrospective cohort analysis was exempt from Institutional Review Board evaluation due to the unidentified population-based nature of the NCDB.

In this study, we included male and female patients, aged 2 years or older, diagnosed with osteosarcoma of the upper extremities at any stage of disease between January 31st, 2004 and December 31st, 2015. We excluded patients with non-osteosarcoma bone tumors and those with osteosarcomas located in sites other than the upper extremities. We also excluded patients who were diagnosed between 2011 and 2015 because they lack a complete a 5-year 
follow-up because the NCDB data ended on December 31, 2015. Inclusion and exclusion criteria are illustrated in Figure 1. Our primary outcome was patient survival, which the NCDB defines as the number of months from the date of diagnosis to the time of death, when patients were lost to follow-up, or the last date of our study. It is important to note that the NCDB does not collect specific cancer survival information.

Our primary independent variables included the following demographic covariates: Age (categorized by group), race, sex, insurance status [private, government (Medicare and Medicaid) or uninsured], income (estimated by average income in the zip code of residence), education level (estimated by percentage of patients with no high school diploma in the zip code of residence), and population density. Age was categorized from 0-14 years (pediatric), 15-39 (adolescent and young adult) and 40 years or older (adult) based on a previous study that categorized age groups in this manner (6). We also included disease characteristics [namely, tumor site, stage of disease and Charlson-Deyo score (comorbidity index)], and treatment characteristics (namely, chemotherapy, radiation surgery, and type of surgery if not radiation). These covariates were selected because they characterize the patient, facility, disease, and treatment variables that might have an impact on patient mortality.

We did not include facility characteristics such as type and location because more than $70 \%$ of patients were lacking such information. This is because the NCDB does not include facility type and facility location information for patients who are 39 years or less in order to protect their identity. Because osteosarcoma is a disease most frequent in young patients, more than $70 \%$ of the population fell in that age group, forcing us to exclude these variables.

We examined the survival differences among patients diagnosed with upper extremity osteosarcoma. A multivariate Cox regression model was used to analyze the impact of patient, disease, and treatment characteristics on the odds of mortality after adjusting for the mentioned covariates. Facility characteristics were not included in our multivariate analysis due to the large percentage of missing information for both covariates. Whether the patient underwent surgery or not was also excluded from the multivariate model due to an insufficient number of patients in the no-surgery group. Patients with missing data were excluded from regression models. Significance was set at $p<0.05$. Statistical analysis was performed using SPSS 25.0 statistical software (IBM, Armonk, NY, USA).

\section{Results}

A total of 26,722 patients diagnosed with bone cancer were identified in the NCDB during the study period, and 591 met inclusion criteria for our study. Mean age $( \pm S D)$ was $30.74 \pm 21.18$ years; $444(76.5 \%)$ patients were White and 123 $(19.3 \%)$ were non-white (Black, Asian, or Native American). Demographic, facility, and disease characteristics are further described in Table I.

In the adjusted Cox regression model (see Table II), we found significant differences in patient-specific characteristics. Our results show that adult patients had significantly higher a higher likelihood of dying from upper limb osteosarcoma than pediatric patients [hazard ratio $(\mathrm{HR})=4.12,95 \% \mathrm{CI}=2.261$ 7.508]. Female patients $(\mathrm{HR}=0.608,95 \% \mathrm{CI}=0.408-0.905)$

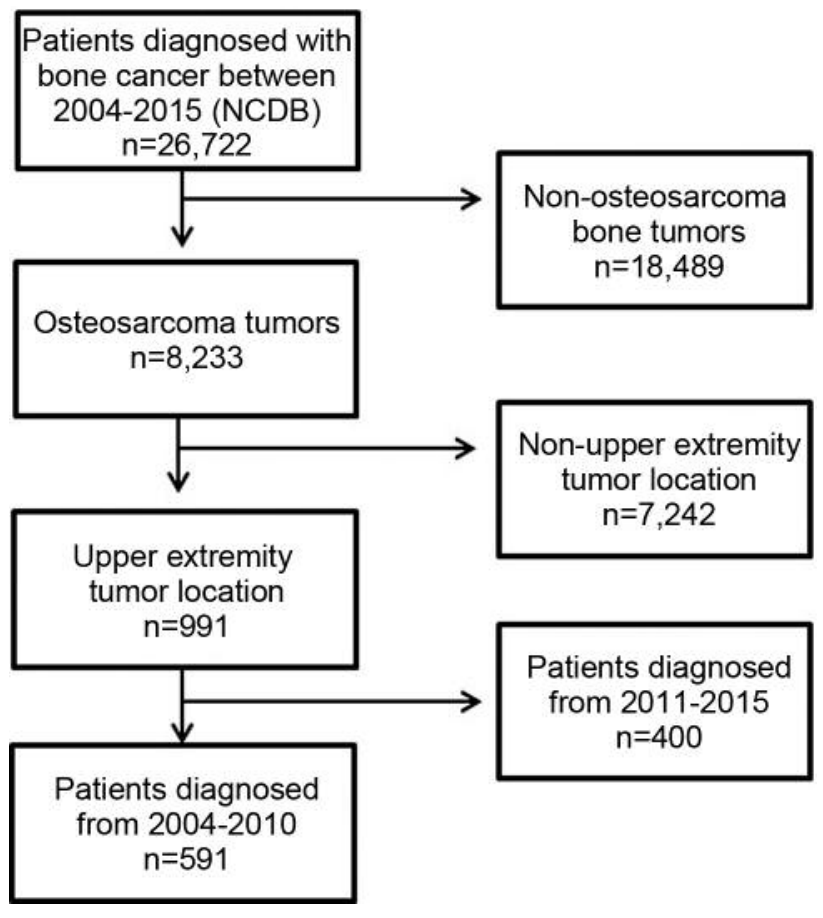

Figure 1. Patient selection criteria.

presented a lower likelihood of death than male patients. When adjusted for confounders, income level showed a significantly higher likelihood of dying for patients with income between $\$ 38,000-\$ 47,999$ ( $\mathrm{HR}=3.335,95 \% \mathrm{CI}=1.694$ $657)$ or less than $\$ 38,000(\mathrm{HR}=2.41,95 \% \mathrm{CI}=1.098-5.288)$. Our results also showed that patients that lived in a zip code in which $13-20.9 \%(\mathrm{HR}=0.459,95 \% \mathrm{CI}=0.221-0.953)$ or more than $21 \%(\mathrm{HR}=0.304,95 \% \mathrm{CI}=0.126-0.731)$ of the population did not graduate high school, had a lower likelihood of dying when compared to patients that lived in a zip code in which under $7 \%$ of the population did not graduate high school. No statistically significant differences were found by insurance and population density.

Tumor-specific characteristics were also shown to affect the survival of patients independently. When compared to those with stage 1 disease, those with stage 2 ( $\mathrm{HR}=4.362$, $95 \% \mathrm{CI}=1.8-10.569)$, stage $3(\mathrm{HR}=8.669,95 \% \mathrm{CI}=2.612-$ 28.764) and stage $4(\mathrm{HR}=14.39,95 \% \mathrm{CI}=5.567-37.192)$ disease had a higher likelihood of dying of upper limb osteosarcoma. Interestingly, comorbidities (assessed with the Charlson-Deyo score) had no statistically significant impact on mortality.

The type of treatment that a patient received was also found to affect mortality in patients with upper limb osteosarcoma. Patients treated with chemotherapy $(\mathrm{HR}=0.891,95 \% \mathrm{CI}=0.476-$ 1.667) had no significant difference in survival when compared 
Table I. Demographic characteristics of patients $(n=591)$.

\begin{tabular}{|c|c|c|c|}
\hline Characteristic & Subgroup & $\mathrm{N}$ & $\%$ \\
\hline \multirow[t]{4}{*}{ Age } & 0-14 Years & 141 & 23.9 \\
\hline & 15-39 Years & 279 & 47.2 \\
\hline & $\geq 40$ Years & 171 & 28.9 \\
\hline & Missing data & 0 & 0 \\
\hline \multirow[t]{3}{*}{ Race } & White & 444 & 75.1 \\
\hline & Other* & 123 & 20.8 \\
\hline & Missing data & 24 & 4.1 \\
\hline \multirow[t]{3}{*}{ Gender } & Male & 334 & 56.5 \\
\hline & Female & 257 & 43.5 \\
\hline & Missing data & 0 & 0 \\
\hline \multirow[t]{4}{*}{ Insurance } & Private & 32 & 5.4 \\
\hline & Government & 334 & 56.5 \\
\hline & Not insured & 192 & 32.5 \\
\hline & Missing data & 33 & 5.6 \\
\hline \multirow[t]{5}{*}{ Average income in zip code } & $>\$ 63,000$ & 170 & 28.8 \\
\hline & $\$ 48,000-62,999$ & 140 & 23.7 \\
\hline & $\$ 38,000-47,999$ & 131 & 22.2 \\
\hline & $<\$ 38,000$ & 138 & 23.4 \\
\hline & Missing data & 12 & 2 \\
\hline \multirow[t]{5}{*}{$\%$ Without HSD in zip code } & $<7.0 \%$ & 138 & 23.4 \\
\hline & $7.0-12.9 \%$ & 160 & 27.1 \\
\hline & $13.0-20.9 \%$ & 153 & 25.9 \\
\hline & $>21.0 \%$ & 128 & 21.7 \\
\hline & Missing data & 12 & 2 \\
\hline \multirow[t]{4}{*}{ Population density } & Metropolitan & 473 & 80 \\
\hline & Urban & 82 & 13.9 \\
\hline & Rural & 18 & 3 \\
\hline & Missing data & 18 & 3 \\
\hline \multirow[t]{4}{*}{ Tumor site } & Forearm, arm, & & \\
\hline & shoulder and joints & 541 & 91.5 \\
\hline & Hand, wrist and joints & 50 & 8.5 \\
\hline & Missing data & 0 & 0 \\
\hline \multirow[t]{5}{*}{ AJCC stage } & I & 73 & 12.4 \\
\hline & II & 233 & 39.4 \\
\hline & III & 21 & 3.6 \\
\hline & IV & 86 & 14.6 \\
\hline & Missing data & 178 & 30.1 \\
\hline \multirow[t]{3}{*}{ Charlson-Deyo score } & 0 & 535 & 90.5 \\
\hline & $\geq 1$ & 55 & 9.3 \\
\hline & Missing data & 1 & 0.2 \\
\hline \multirow[t]{3}{*}{ Chemotherapy } & No & 115 & 19.5 \\
\hline & Yes & 465 & 78.7 \\
\hline & Missing data & 11 & 1.9 \\
\hline \multirow[t]{3}{*}{ Radiation } & No & 542 & 91.7 \\
\hline & Yes & 36 & 6.1 \\
\hline & Missing data & 13 & 2.2 \\
\hline \multirow[t]{3}{*}{ Surgery } & No & 105 & 17.8 \\
\hline & Yes & 460 & 77.8 \\
\hline & Missing data & 31 & 3.1 \\
\hline \multirow[t]{4}{*}{ Type of surgery } & Local excision with & & \\
\hline & limb salvage & 369 & 62.4 \\
\hline & Amputation of limb & 86 & 14.6 \\
\hline & Missing data & 136 & 23 \\
\hline
\end{tabular}

HSD: High school diploma; AJCC: American Joint Committee on Cancer. *Black, Asian and Native American.
Table II. Hazard ratios of dying from upper limb osteosarcoma.

\begin{tabular}{|c|c|c|c|}
\hline Factor & HR & $95 \% \mathrm{CI}$ & $p$-Value \\
\hline \multicolumn{4}{|l|}{ Age } \\
\hline $0-14$ years & 1 & & \\
\hline $15-39$ years & 1.319 & $0.732-2.376$ & 0.357 \\
\hline$\geq 40$ years & 4.12 & $2.261-7.508$ & $<0.001$ \\
\hline \multicolumn{4}{|l|}{ Race } \\
\hline White & 1 & & \\
\hline Others* & 0.742 & $0.445-1.238$ & 0.253 \\
\hline \multicolumn{4}{|l|}{ Sex } \\
\hline Male & 1 & & \\
\hline Female & 0.608 & $0.408-0.905$ & 0.014 \\
\hline \multicolumn{4}{|l|}{ Insurance } \\
\hline Private & 1 & & \\
\hline Government & 1.278 & $0.527-3.101$ & 0.587 \\
\hline Not insured & 1.988 & $0.785-5.036$ & 0.147 \\
\hline \multicolumn{4}{|l|}{ Average income in zip code } \\
\hline$\geq \$ 63,000$ & 1 & & \\
\hline$\$ 48,000-62,999$ & 1.565 & $0.796-3.075$ & 0.194 \\
\hline$\$ 38,000-47,999$ & 3.335 & $1.694-6.567$ & $<0.001$ \\
\hline$\leq \$ 38,000$ & 2.41 & $1.098-5.288$ & 0.028 \\
\hline \multicolumn{4}{|l|}{ Without HSD in zip code } \\
\hline$<7.0 \%$ & 1 & & \\
\hline $7.0-12.9 \%$ & 0.6 & $0.314-1.146$ & 0.122 \\
\hline $13.0-20.9 \%$ & 0.459 & $0.221-0.953$ & 0.037 \\
\hline$\geq 21.0 \%$ & 0.304 & $0.126-0.731$ & 0.008 \\
\hline \multicolumn{4}{|l|}{ Population density } \\
\hline Metropolitan & 1 & & \\
\hline Urban & 0.834 & $0.471-1.476$ & 0.533 \\
\hline Rural & 0.792 & $0.208-3.018$ & 0.733 \\
\hline \multicolumn{4}{|l|}{ Tumor site } \\
\hline Forearm, arm, shoulder and joints & 1 & & \\
\hline Hand, wrist and joints & 0.437 & $0.132-1.446$ & 0.175 \\
\hline \multicolumn{4}{|l|}{ AJCC stage } \\
\hline I & 1 & & \\
\hline II & 4.362 & $1.8-10.569$ & 0.001 \\
\hline III & 8.669 & $2.612-28.764$ & $<0.001$ \\
\hline IV & 14.39 & $5.567-37.192$ & $<0.001$ \\
\hline \multicolumn{4}{|l|}{ Charlson-Deyo score } \\
\hline 0 & 1 & & \\
\hline$\geq 1$ & 1.431 & $0.766-2.672$ & 0.261 \\
\hline \multicolumn{4}{|l|}{ Chemotherapy } \\
\hline No & 1 & & \\
\hline Yes & 0.891 & $0.476-1.667$ & 0.718 \\
\hline \multicolumn{4}{|l|}{ Radiation } \\
\hline No & 1 & & \\
\hline Yes & 2.457 & $1.056-5.717$ & 0.037 \\
\hline \multicolumn{4}{|l|}{ Type of surgery } \\
\hline Local excision with limb salvage & 1 & & \\
\hline Amputation of limb & 1.902 & $1.18-3.064$ & 0.008 \\
\hline
\end{tabular}

CI: Confidence intervaI; HR: hazard ratio; HSD: high school diploma; AJCC: American Joint Committee on Cancer. *Black, Asian and Native American.

to patients who did not receive chemotherapy. However, for patients who received radiation therapy $(\mathrm{HR}=2.457$, 95\% CI=1.056-5.717) the likelihood of dying was significantly increased when compared to patients who did not receive 
radiation therapy. For patients who underwent a limb amputation $(\mathrm{HR}=1.902,95 \% \mathrm{CI}=1.18-3.064)$, the likelihood of dying was also increased when adjusted for confounders.

\section{Discussion}

Osteosarcoma of the upper extremities is an uncommon type of cancer that has a bimodal peak incidence, presenting more commonly in adolescents and patients older than 60 years. Its 5-year survival rate has increased significantly with the introduction of chemotherapeutic agents into the treatment. However, for the past 30 years, survival has not improved, and new drugs have failed to reduce the mortality of osteosarcoma. The importance of this study relies on its public health approach instead of a pharmacological or surgical approach. It was our intent to identify factors that affect mortality and which can be modified from a public health point of view.

The results of this study showed that osteosarcoma of the upper extremities led to significantly higher mortality in adult patients, even when adjusted for factors such as comorbidities and stage. The results of this study are congruent with a previous study that showed poor prognosis in elderly patients (7). The second peak of incidence of osteosarcoma occurs after 60 years of age and is more commonly a secondary malignancy, usually associated with Paget disease or previous radiation (8). Osteosarcoma in elderly patients is known to present more commonly on the axial skeleton (6), which has been demonstrated to have a higher incidence of metastasis at diagnosis (9). This tumor site location has been proposed as one of the explanations for worst prognosis; however, our study excluded patients with axial skeleton osteosarcoma. Another possible reason for increased mortality in elderly patients with osteosarcoma is a lower response to chemotherapy, which is known to be one of the major predictive factors of survival (10). It has been stated that $90 \%$ or more tumor necrosis with chemotherapy treatment is a sign of good prognosis (10). There is no established standard treatment for this population and administering chemotherapy is still controversial (7). Furthermore, older patients have a lower renal clearance than children and therefore might present a lower tolerance to methotrexate treatment (11).

Our results also showed that the estimated average household income of patients had a statistically significant effect on survival. This was particularly true for the groups with a lower income $(\$ 38,000-47,999$ and $<\$ 38,000)$. Several studies have previously demonstrated for other types of cancer that socioeconomic status can be deleterious to survival, particularly if the patient belongs to the lower income groups (12). Although the causality of these findings is hard to assess, it is likely that lower income, education, awareness, access to specialty care, adherence to treatment, time to diagnosis and compliance with long-term surveillance are factors that contribute to the lower survival of these patients (13). A previous study of NCDB data showed that patients with high-grade osteosarcoma with a low socioeconomic status had diminished overall survival (14).

Regarding patient race, our results showed no significant difference in survival when adjusting for confounders. This is not congruent with a previous study on Ewing sarcoma that showed that factors such as ethnicity to have a significant impact on overall survival (63 months for White non-Hispanic, and 23 months for Hispanic) (15). When studying breast cancer survival, race has also been shown to be a significant prognostic factor that negatively affects survival for minorities (16). Correlations between racial minorities with lower income and education average have shown that poorer outcomes in racial minorities can be due to socioeconomic disparities rather than true biological disparities (16). Considering that previous studies have found racial disparities in patients with Ewing sarcoma and breast cancer, it is possible that no disparities were found in our study due to a substantial number of patients with missing information, thereby reducing the power of the study.

Not surprisingly, we found that patients diagnosed with higher stage disease had higher mortality. This is true for most cancer types and stage is commonly used as a predictor of prognosis. The significance of this finding relies on the fact that if early detection, patient awareness, and education can be improved, we a significant decrease in mortality in patients with upper limb osteosarcoma could potentially be achieved.

Unlike Ewing sarcoma, conventional osteosarcoma (except the rare small-cell variant) is believed to be relatively resistant to radiotherapy (17). Radiotherapy is not recommended as adjuvant therapy or as replacement for surgery (18). It can be considered in patients who refuse or are not candidates for surgery due to comorbidities or anatomical location of the tumor (18). The results of this study show that patients with upper extremity osteosarcoma who received radiation therapy were more likely to die than patients that did not. As mentioned previously, this treatment is only used in patients who, for whatever reason, are not candidates for complete surgical excision of the tumor. This concords with our findings for our cohort, which had a higher proportion of patients with stage 3 and stage 4 disease in the group that received radiotherapy when compared to the group without radiotherapy. When given radiotherapy, it is possible that most of these patients were beyond a curable stage of cancer.

Our study has several limitations. Due to the retrospective nature using a large national database, we were unable to verify the accuracy of the data. A large proportion of patient records were missing information on facility type and location, causing us to remove these variables from multivariate 
analysis. Furthermore, education and income levels were based on averages in the zip code of residence rather than those of the actual patient, which leads to assumptions that are not necessarily true. Moreover, the NCDB does not include information on response to chemotherapy, which is an important factor used to determine prognosis in this disease.

Osteosarcoma of the upper extremities is an uncommon disease with a mortality that has not changed significantly in the past 30 years. Our analysis showed that age, gender, income, education, stage at diagnosis, radiation therapy and type of surgery seem to affect the mortality of patients with this condition. From a public health stand point, some of these factors can be addressed and, therefore, efforts should be made to reduce the mortality of upper extremity osteosarcoma.

\section{Conflicts of Interest}

No Authors present conflicts of interest in regard to this study.

\section{Authors' Contributions}

All Authors contributed to the study design, commented on previous versions of the article, read and approved the final article. Material preparation, data collection and analysis were performed by DJR, ACS and AJF. The first draft of the article was written by DJR and MTH.

\section{References}

1 Wang $\mathrm{X}$, Zheng $\mathrm{H}$, Shou $\mathrm{T}$, Tang $\mathrm{C}$, Miao $\mathrm{K}$ and Wang $\mathrm{P}$ : Effectiveness of multi-drug regimen chemotherapy treatment in osteosarcoma patients: A network meta-analysis of randomized controlled trials. J Orthop Surg Res 12(1): 52, 2017. PMID: 28356114. DOI: 10.1186/s13018-017-0544-9

2 Kumar R, Kumar M, Malhotra K and Patel S: Primary osteosarcoma in the elderly revisited: Current concepts in diagnosis and treatment. Curr Oncol Rep 20(2): 13, 2018 PMID: 29492676. DOI: 10.1007/s11912-018-0658-1

3 Friedman MA and Carter SK: The therapy of osteogenic sarcoma: Current status and thoughts for the future. J Surg Oncol 4(5): 482-510, 1972. PMID: 4566220.

4 Senerchia AA, Macedo CR, Ferman S, Scopinaro M, Cacciavillano W, Boldrini E, Lins de Moraes VL, Rey G, de Oliveira CT, Castillo L, Almeida MT, Borsato ML, Lima E, Lustosa D, Barreto JH, El-Jaick T, Aguiar S, Brunetto A, Greggiani L, Cogo-Moreira H, Atallah A and Petrilli AS: Results of a randomized, prospective clinical trial evaluating metronomic chemotherapy in nonmetastatic patients with highgrade, operable osteosarcomas of the extremities: A report from the Latin American Group of osteosarcoma treatment. Cancer 123(6): 1003-1010, 2017. PMID: 28263383. DOI: 10.1002/ cncr.30411

5 Bilimoria KY, Stewart AK, Winchester DP and Ko CY: The National Cancer Data Base: A powerful initiative to improve cancer care in the United States. Ann Surg Oncol 15(3): 683690, 2008. PMID: 18183467. DOI: 10.1245/s 10434-007-9747-3
6 Iwata S, Ishii T, Kawai A, Hiruma T, Yonemoto T, Kamoda H, Asano $\mathrm{N}$ and Takeyama M: Prognostic factors in elderly osteosarcoma patients: A multi-institutional retrospective study of 86 cases. Ann Surg Oncol 21(1): 263-268, 2014. PMID: 23975321. DOI: 10.1245/s10434-013-3210-4

7 Nishida Y, Isu K, Ueda T, Nishimoto Y, Tsuchiya H, Wada T, Sato K, Tsukushi S and Sugiura H: Osteosarcoma in the elderly over 60 years: A multicenter study by the Japanese Musculoskeletal Oncology Group. J Surg Oncol 100(1): 48-54, 2009. PMID: 19384906 . DOI: $10.1002 /$ jso. 21287

8 Ottaviani $\mathrm{G}$ and Jaffe $\mathrm{N}$ : The epidemiology of osteosarcoma. Cancer Treat Res 152: 3-13, 2009. PMID: 20213383. DOI: 10.1007/978-1-4419-0284-9_1

9 Bielack SS, Wulff B, Delling G, Gobel U, Kotz R, Ritter J and Winkler K: Osteosarcoma of the trunk treated by multimodal therapy: Experience of the Cooperative Osteosarcoma Study Group (COSS). Med Pediatr Oncol 24(1): 6-12, 1995. PMID: 7968796.

10 Joo MW, Kang YK, Yoo CY, Cha SH and Chung YG: Prognostic significance of chemotherapy-induced necrosis in osteosarcoma patients receiving pasteurized autografts. PLoS One 12(2): e0172155, 2017. PMID: 28196121. DOI: 10.1371/journal.pone. 0172155

11 Yang Y, Wang X, Tian J and Wang Z: Renal function and plasma methotrexate concentrations predict toxicities in adults receiving high-dose methotrexate. Med Sci Monit 24: 7719-7726, 2018. PMID: 30369593. DOI: 10.12659/MSM.912999

12 Melvan JN, Sancheti MS, Gillespie T, Nickleach DC, Liu Y, Higgins K, Ramalingam S, Lipscomb $\mathrm{J}$ and Fernandez FG: Nonclinical factors associated with 30-day mortality after lung cancer resection: An analysis of 215,000 patients using the National Cancer Data Base. J Am Coll Surg 221(2): 550-563, 2015. PMID: 26206651. DOI: 10.1016/j.jamcollsurg.2015.03.056

13 Crawford SM, Sauerzapf V, Haynes R, Forman D and Jones AP: Social and geographical factors affecting access to treatment of colorectal cancer: A cancer registry study. BMJ Open 2(2): e000410, 2012. PMID: 22535788. DOI: 10.1136/bmjopen-2011-000410

14 Miller BJ, Gao Y and Duchman KR: Socioeconomic measures influence survival in osteosarcoma: An analysis of the National Cancer Data Base. Cancer Epidemiol 49: 112-117, 2017. PMID: 28601784. DOI: 10.1016/j.canep.2017.05.017

15 Koohbanani B, Han G, Reed D, Zhao Q, Yi D, HendersonJackson E and Bui MM: Ethnicity and age disparities in Ewing sarcoma outcome. Fetal Pediatr Pathol 32(4): 246-252, 2013. PMID: 23043418. DOI: 10.3109/15513815.2012.721480

16 Newman LA and Kaljee LM: Health disparities and triplenegative breast cancer in African American women: A review. JAMA Surg 152(5): 485-493, 2017. PMID: 28355428. DOI: 10.1001/jamasurg.2017.0005

17 Stea B, Cavazzana A and Kinsella TJ: Small-cell osteosarcoma: Correlation of in vitro and clinical radiation response. Int J Radiat Oncol Biol Phys 15(5): 1233-1238, 1988. PMID: 3182355.

18 DeLaney TF, Park L, Goldberg SI, Hug EB, Liebsch NJ, Munzenrider JE and Suit HD: Radiotherapy for local control of osteosarcoma. Int J Radiat Oncol Biol Phys 61(2): 492-498, 2005. PMID: 15667972. DOI: 10.1016/j.ijrobp.2004.05.051

Received July 26, 2019

Revised August 8, 2019

Accepted August 9, 2019 